\title{
Impingement of coaxial jet on convex element for confined and unconfined flow
}

\author{
A.M. Hanchinal ${ }^{1}$ and V.V. Katti ${ }^{2}$ \\ 1 Department of Mechanical Engineering, Jain C. E. T., Hubballi, Karnataka, India-580031. \\ Phone: +91-9740169907 \\ ${ }^{2}$ KLS VDIT, Haliyal, Karnataka, India-581329
}

\begin{abstract}
Jet impingement is most effective and active method for cooling and heating of any surface or system. The ability of jet impingement is greatly influenced by nozzle configuration and other dimensional and non-dimensional parameters. Impinging coaxial swirl jet generates interesting flow filed on any test surface and influences both pressure and heat distribution on impinging surfaces. In present study, an experimental investigation is carried to analyze the effects of turbulent coaxial swirl jet on the pressure distribution $\left(P_{c} \& P_{c o}\right)$ on convex element. For better and acceptable results, the desirable parameters are identified from previous research works. The present experimental result highlights the independency of pressure coefficient $\left(P_{C}\right)$ for jetReynolds number $(R e=70000$ to 45000$)$, effect of circumferential angle $(\theta)$ or inclination of test element, effect of jet exit to test element distance $(Z / d h)$ and effect of confinement on $P_{c} \& P_{c o}$ pattern on a convex test element. The higher pressure coefficient value are obtained at lower $Z / d h$ $=1 \&$ at $\theta=15^{\circ}$ to $12^{\circ}$ and significant drop in the values are seen with increase in the $Z / d h \& \theta$. At $\theta=20^{\circ}$ to $30^{\circ}$ the value of $P_{c} \& P_{c o}$ reaches to negative magnitude. The use of confinement tube enhancementthe pressure distribution $\left(P_{C} \& P_{C 0}\right)$ by $61 \%$ to $64 \%$ is seen for the same flow conditions.
\end{abstract}

ARTICLE HISTORY

Revised: $19^{\text {th }}$ Nov 2019

Accepted: $25^{\text {th }}$ Nov 2019

\section{KEYWORDS}

Jet impingement; co-axial jet;

pressure coefficient; swirl flow;

convex test element.

\section{INTRODUCTION}

Jet impingement is an active approach for heating and cooling of surfaces. In jet impingement method the flow of fluid (liquid or gases) is accelerated to high velocity through a designed nozzles or orifice and is made to impinging on surface involved in the process. Due to better results and feasibility, jet impingent have given scope to adopt it in various thermal related applications like cooling of turbine blades, combustion chamber walls in gas turbine engines, glass processing industries, cooling of electronic circuits and equipment's and surface treatment of metals [1, 2]. The performance of an impinging method is greatly influenced by parameters such as structure of jet, impingement distance, jet configuration, confined and unconfined flow, flow type and type of fluid. In this regard, numbers of experimental and numerical studies are carried and came with some acceptable results. In the last few decades, numerous works are done using conventional jet but a recent research works given importance on use of swirl jet to provide an alternative to convention jets. Swirl jet flow can be achieved by many ways and this flow is created a great potential in relevant research area. Some of experimentation concluded that, the better mixing of the flow and vortices generation gives good results in a jet impingement, which can be achieved by well-defined nozzles creating swirling co-axial flows [1-5] thus, an attempt is made to conduct experiment using coaxial jet flow to analyze the distribution of pressure coefficients on convex test surface for both confined and unconfined flow.

The research on coaxial jet flow given scope for the developments in burner design and configuration, stabilization of flame, combustion units, etc. The vertex formation is key factor in jet impingement study. Adzlan and Gotoda [6] highlighted the vertex formation and breakdown in the swirling coaxial jet. Ianiro and Cardone [7] used single and multiple swirl jet and compared experimental results with circular jet. Nuntadusit et al. [8] conducted similar experimental study using multiple swirling jet and oil film technique is used analyze flow pattern of jet. Lu et al. [9] studied the mass flow rate using high speed flow visualization method. Later New and Tsioli [10] used $45^{\circ}$ and $60^{\circ}$ inclined coaxial jets are to impinge experimentally on test surface. Fenot et al. [11] adopted high speed and infrared thermography methods to identify the behavior of hot jets $(R e=23,000$ to 33,000) on flat plate. Wannassi and Monnoyer [12] carried numerical and experimental study and identified the flow and heat transfer characteristics on flat plate using swirl jet and also compared the results with conventional round jet. Eiamsa-ard et al. [13] used co/counter-dual swirling impinging jets to study heat transfer over flat plate for jet Reynolds number 5,000 to 20,000.

Boualia et al. [14] carried study using new configuration of tri-coaxial jet, they carried experiment to understand the dynamics of tri-coaxial burner. By considering a swirl number in the range 0 to 1.31 and swirl vanes up to $60^{\circ}$, Balakrishnan and Srinivasan [15] conducted an experiment using coaxial jet to reduce jet noise along with nozzle pressure are identified from 0.18 to 6 and they concluded that at subsonic zone weak swirl will be more effective in reduction of noise. The numerical study by Chouaieb et al. [16] with coaxial jet highlights the dynamic structure and the mixing of jet 
in the confined zone. The effect of turbulent jet will have more impact on both fluid and heat characteristics when impingement is made at lower distance and it also provides better mixing due to which sudden peaks are seen in the values $[17,18]$. Zeiny et al. [19] studied heat transfer over flat hot plate by impinging swirl jet with different twist number of 0 , 5, 8, 10 and 12 for Reynolds number 20,000. Higher Nusselt number are obtained for swirl jet when compared with convectional jet and for 12 twist swirl jet around 29\% higher value of Nusselt number are observed. Recently, Markal $[20,21]$ used coaxial jet for confined flow to identify the effect flow ratio $0.25,0.5,0.75$ and dimensionless impingement distance from 0.25 to 2.5 on heat and pressure destitution on convex surface and compared the results with conventional jet.

Some other studies highlight the use of multiple swirling jet, effect of twist ratio, jet to test surface distance on the heat transfer distribution [22-29]. But, most of the studies are related to identify heat transfer characteristics over flat plate for unconfined flow at various flow conditions and only in few studies co-axial swirl jet is considered to impinge on test surface. Therefore, to fill this gap the present work an attention is given to identify pressure distribution $(P c$ and $P c o$ ) characteristic by experimentally impinging swirling co-axial air jet on smooth hemispherical element (convex) for both confined and unconfined flow for various flow and geometric conditions and the results obtained will be useful in jet impingement applications and for other research studies.

\section{EXPERIMENTATION AND METHODOLOGY}

The schematic experimental layout for present study is shown in Figure 1. The air blower is used as primary source for impingement of air through a coaxial jet, the blower delivers $3.1 \mathrm{~m}^{3} / \mathrm{min}$ of air with pressure on $600 \mathrm{~mm}$ of water when operating under 12,000 rpm. A convex smooth element of outer diameter $50 \mathrm{~mm}$ with $5 \mathrm{~mm}$ thickness and $300 \mathrm{~mm}$ effective test length is taken as test element. The air coming out from blower is maintained at stable pressure of 1 bar using calibrated regulator. The jet Reynolds number is obtained from calibrated venturimeter with $C_{d} \pm 0.92$ by adjusting control valves and air coming out at particular Reynolds number is made to impinge on the test element through coaxial jet in confined and unconfined flow. For completely developed flow at jet exit, the pipe length is taken 100 times the hydraulic diameter $(d h)$ and the nozzle length to diameter ratio is to be taken as 83. Similar experimental method is used in the study carried to analyze effect of orifice geometry on pressure distribution by Hanchinal and Katti [28].

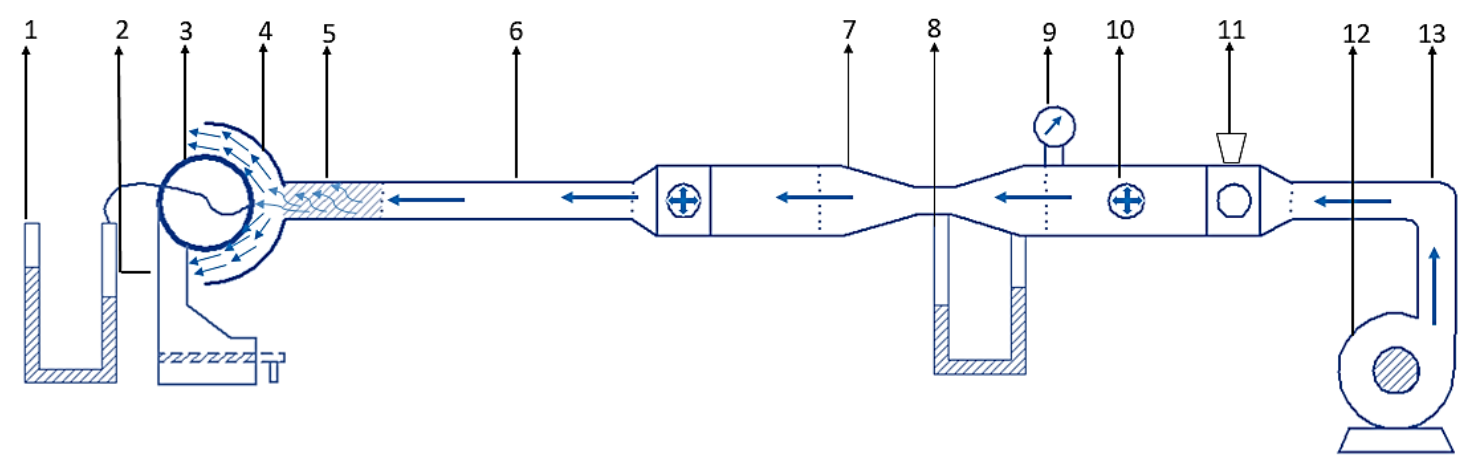

(1. Manometer to Measure Wall Static Pressure, 2. Adjustable Table, 3. Test Element, 4. Confinement Tube, 5. Coaxial Generator, 6. Tube or Pipe, 7. Venturimeter, 8. Manometer to Measure Re, 9. Pressure Indicator, 10. Control Value, 11. Pressure Regulator, 12. Air blower, 13. Flexible Pipe.)

Figure 1. Schematic representation of experimental setup.

Calibrated two-axis adjustable table is used to maintain test element at $Z / d h$ (1 to 4 ) position. The $P c$ and $P c o$ on test element is measured with help of pressure tap created at the back surface of test element. A probe of $0.5 \mathrm{~mm}$ diameter is inserted in the pressure tap till the outer surface without disturbing the flow. A free movement is given to pressure tap so that $P c$ can be measured at various surface angle on test element. The air is blown through coaxial jet configuration at various identified $R e$ and $Z / d h$ mentioned. The flow restriction on test element is made with help of confinement tube arrangement A concave tube of diameter $65 \mathrm{~mm}$ with thickness $2.5 \mathrm{~mm}$ and length same as of test element is used, so that the jet flow in well-defined channel after the impingements on test element as shown in Figure 2(a). Complete experiment is to be performed under a steady state condition at identified parameter given in Table 1. Different plots are drawn for the obtained values to conclude the study. The coaxial swirl jet configuration having hydraulic diameter 11.8 $\mathrm{mm}$ is shown in Figure 3. 


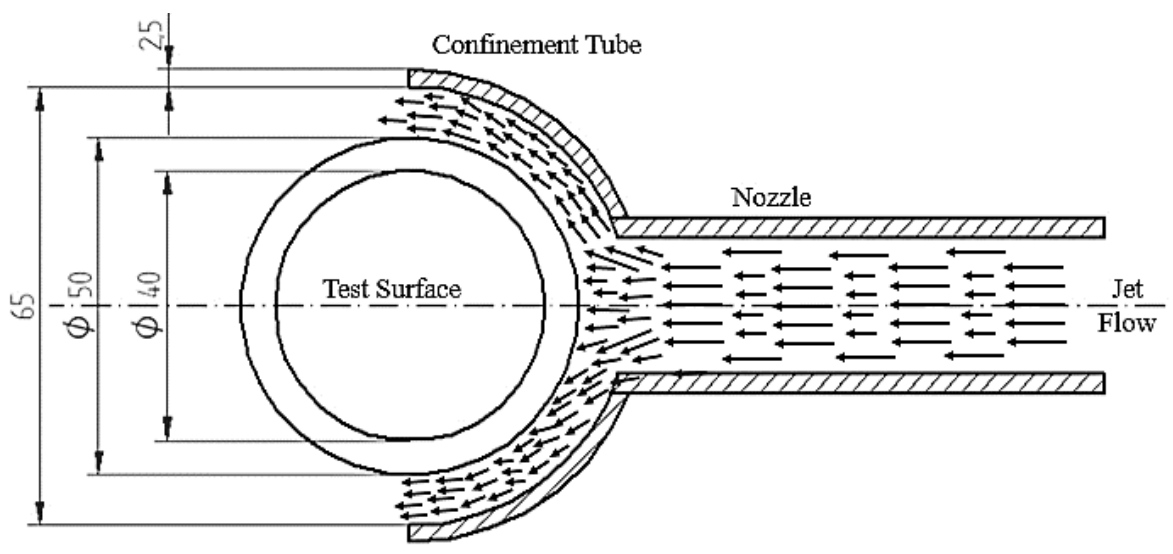

(a) Confined flow

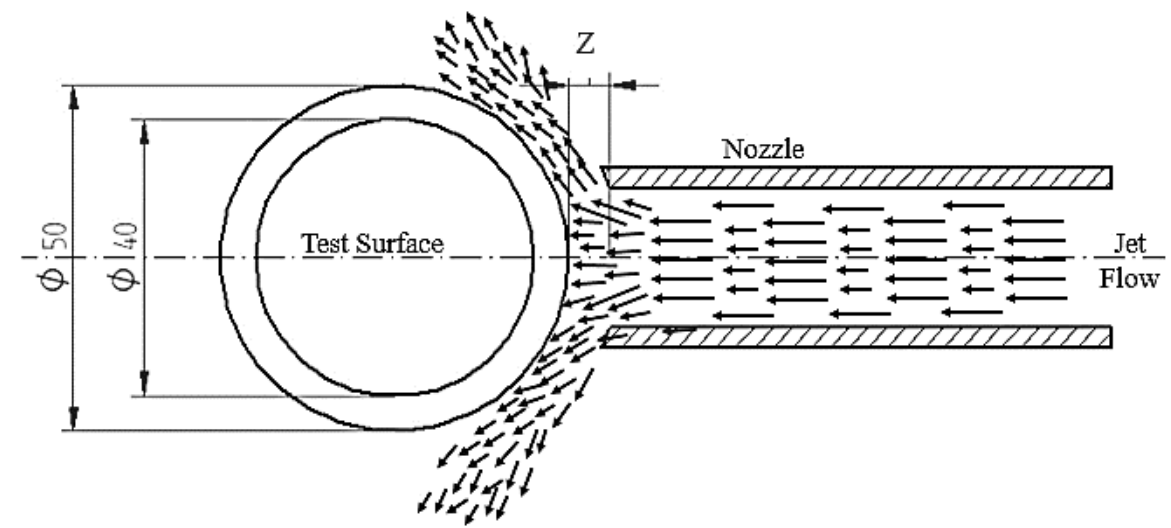

(b) Unconfined flow

Figure 2. Schematic view of jet flow over convex element.
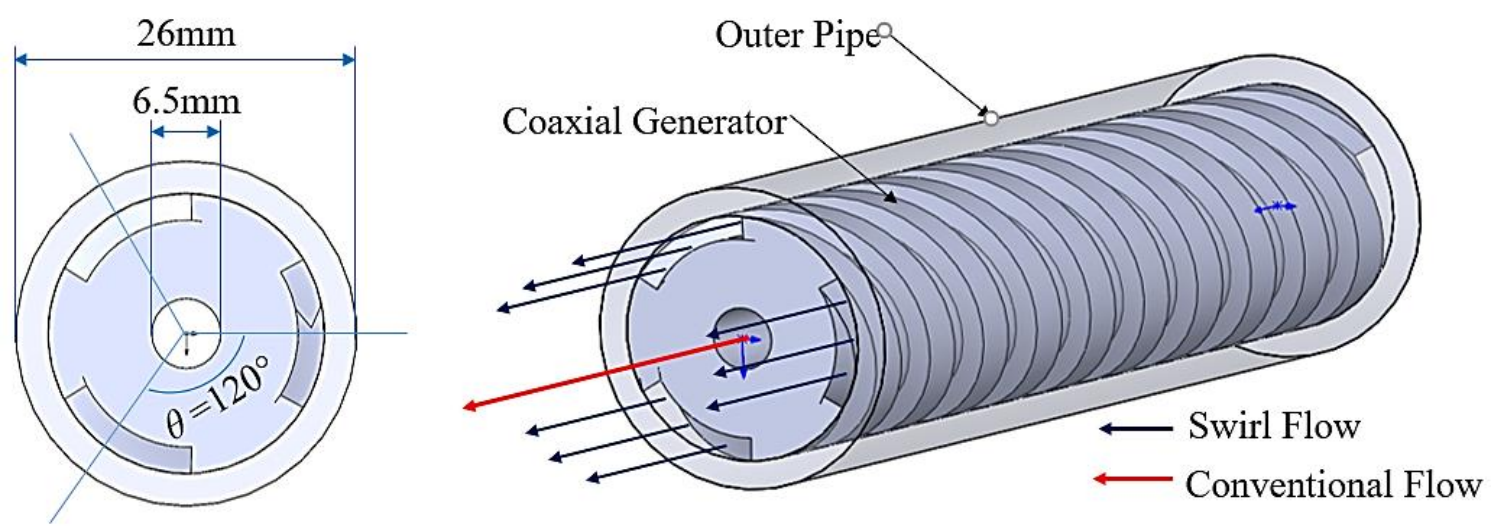

Figure 3. Schematic view of swirl-coaxial jet configuration. 
Table 1. Parameters considered in the study.

\begin{tabular}{ccccc}
\hline $\begin{array}{c}\text { Test } \\
\text { element }\end{array}$ & $\begin{array}{c}\text { Jet Reynolds } \\
\text { Number }(R e)\end{array}$ & $\begin{array}{c}\text { Circumferential } \\
\text { angle }(\theta)\end{array}$ & $\begin{array}{c}\text { Nozzle to test } \\
\text { section }(Z / d h)\end{array}$ & Flow Type \\
\hline Convex & 70,000 to 45,000 & $0^{\circ}$ to $50^{\circ}$ & 1 to 4 & $\begin{array}{c}\text { Confined and } \\
\text { Unconfined Flow }\end{array}$ \\
\hline
\end{tabular}

\section{RESULTS AND DISCUSSION}

In the present study, the experimental impingement of coaxial air jet on convex element is conducted at various parameters like dimensionless nozzle exit-to-test surface $(Z / d h)$, circumferential angle of test surface $(\theta)$ and Reynolds number given in Table 1. The measurement $P c \& P c o$ on test element is done with high precision using calibrated devises under study state condition. Results obtained are used to draw different plots are drawn for analyses and also the results of confined flow are compared with unconfined flow.

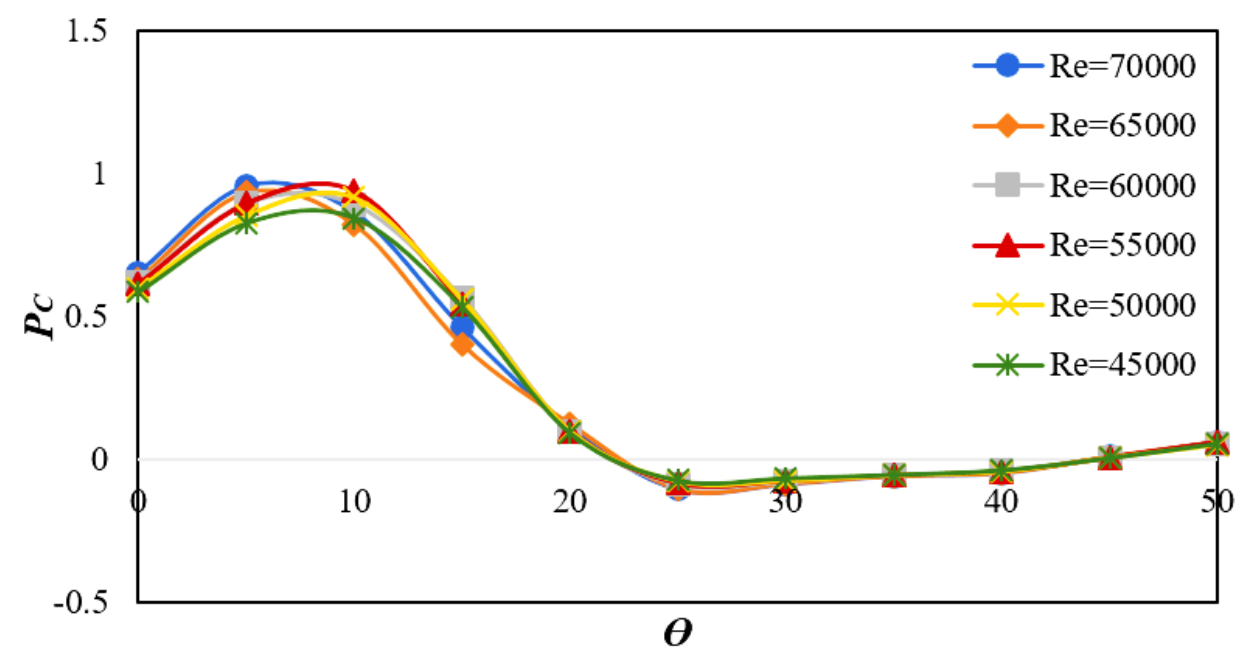

Co-axial swirl jet, $Z / d h=1, D / d h=3.125$

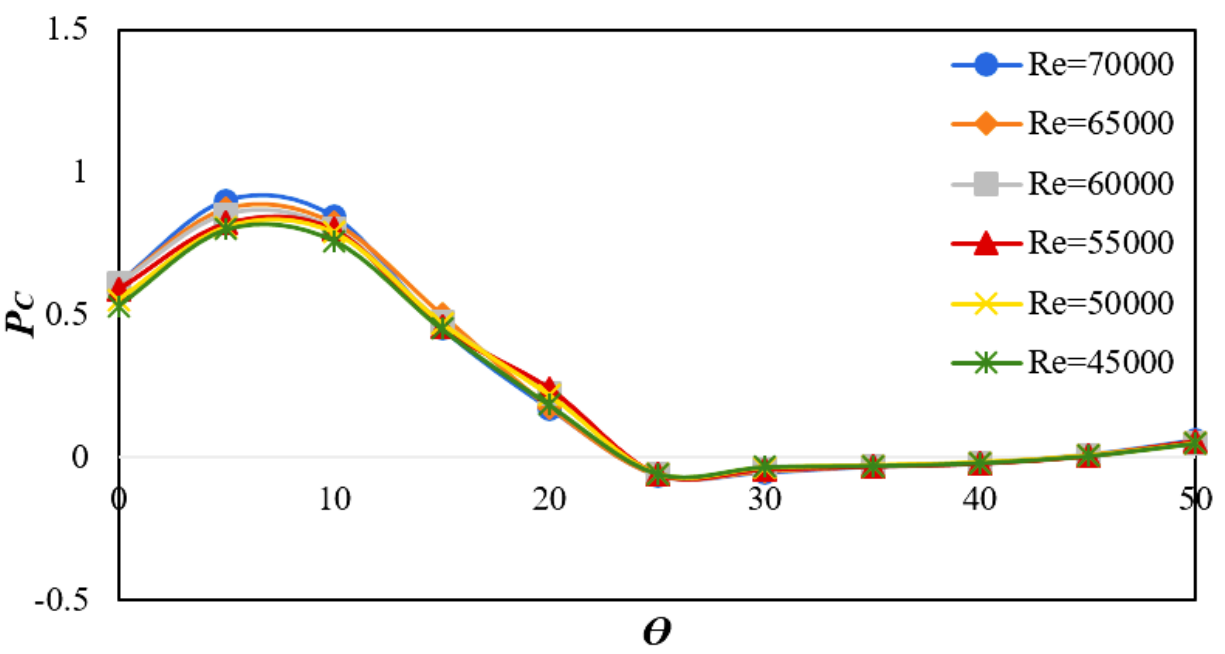

Co-axial swirl jet, $Z / d h=2, D / d h=4.237$

Figure 4. Variation of pressure coefficient along the curvature for unconfined flow.

\section{Influence of Jet Reynolds Number $(R e)$ on Wall Static Pressure}

The non-dimensional Reynolds number helps to describe the flow of an any fluid. In present study, at various jet Reynolds number the non-dimensional value of $P_{C}$ and $P_{C O}$ are identified at different $Z / d h$ for both confined and unconfined jet flow. Figure 4 and 5 shows the $P c$ distribution along circumferential distance $\theta$ of test element at $Z / d h=1$ and 2. The plot $P c$ vs $\theta$ shows independent behaviour of pressure coefficients for all jet Reynolds number, as all the curves 
take same nature for all jet $R e(70,000-45,000)$ and $P c$ value decreases with increase in $\theta$, similar independence nature of jet Re over Pc and Pco are seen in early studies [22, 23, 28]. The coaxial jets provide multiple mixing zones which is key factor for primary and secondary peaks in the heat and pressure distribution study, which is clearly highlighted by Ahmed et al. [18]. At stagnation point the pressure coefficients $\left(P_{C O}\right)$ will be in the rage of 1.1 to 0.5 but, in the present study significant peaks in the distribution of $\mathrm{Pc}$ are observed between $5^{\circ}$ to $10^{\circ}$ and these values are much higher compared to stagnation point values and these values are in the range of 1.45 to 0.75 . Based on the remarks from Markal [20, 21], peak values are seen in each mixing zones and the shear rate in these zones is the key parameter for these peaks. It is also observed that the $P c$ and $P_{C O}$ are dependent on flow restriction and jet exit distance $(Z / d h)$ which are discussed in further sections.

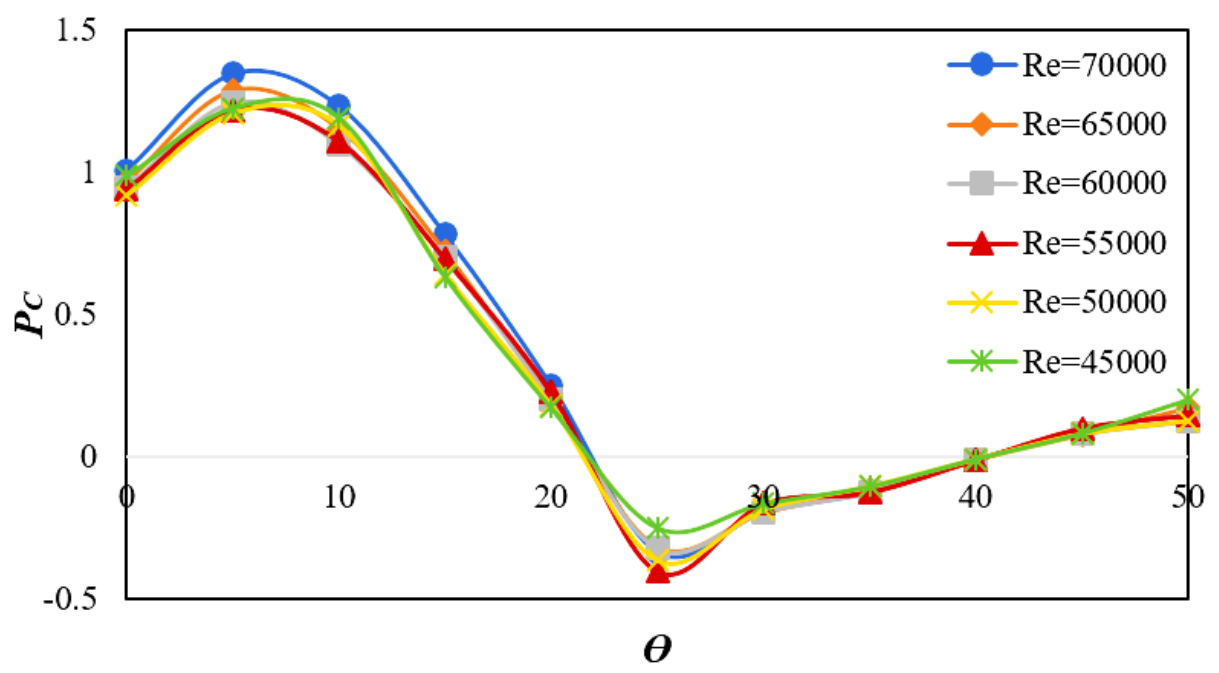

Co-axial swirl jet, $Z / d h=1, D / d h=4.237$

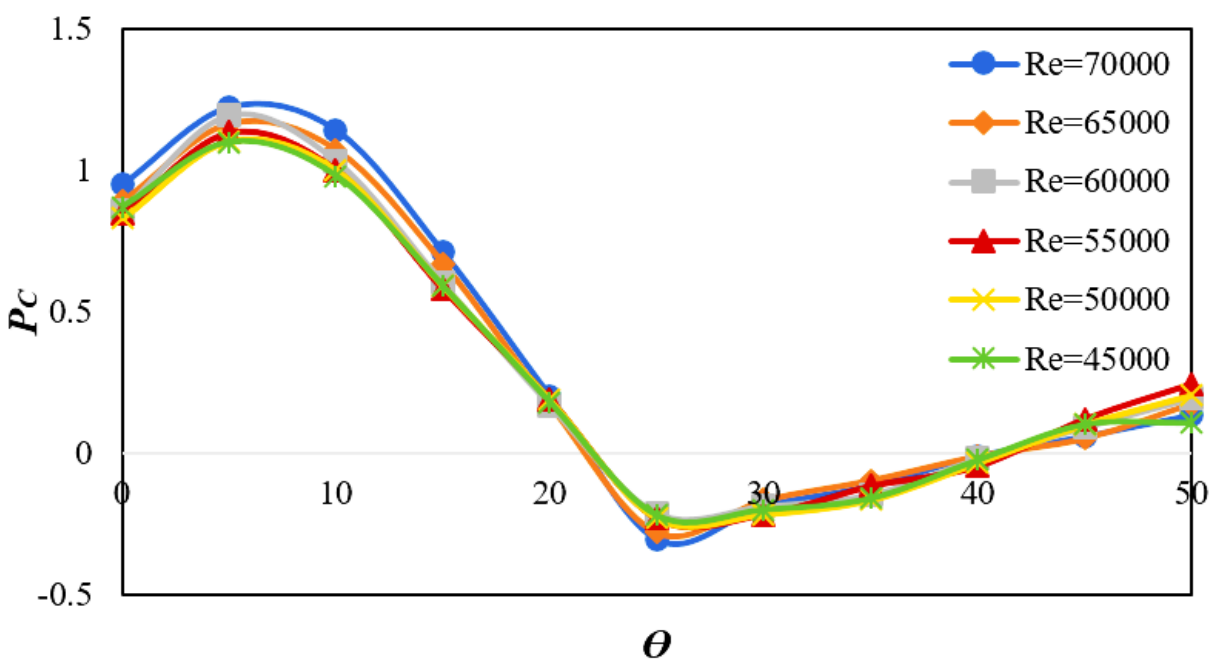

Co-axial swirl jet, $Z / d h=2, D / d h=4.237$

Figure 5. Variation of pressure coefficient along the test element curvature for confined flow. 

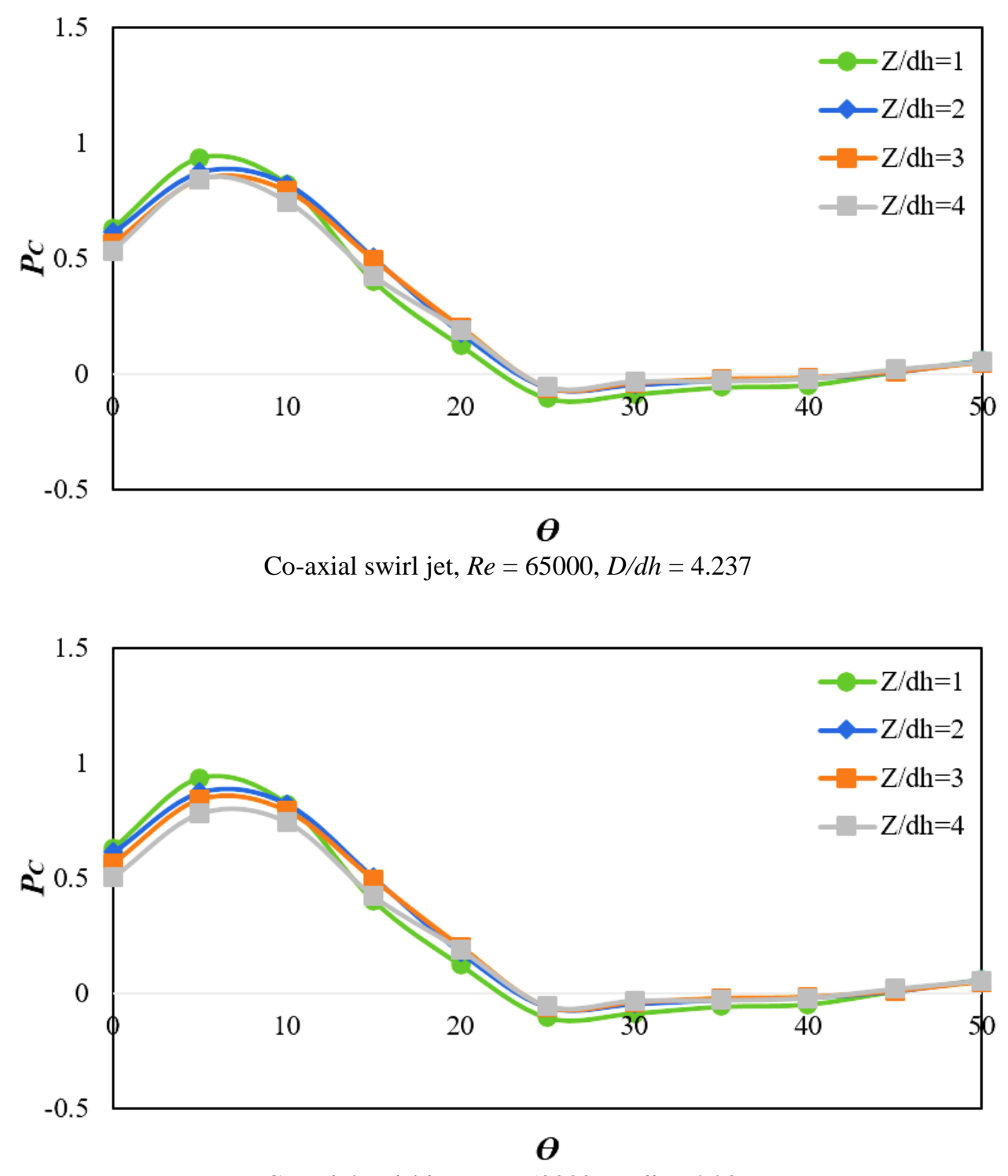

Co-axial swirl jet, $R e=50000, D / d h=4.237$

Figure 6. Variation of pressure coefficient with jet exit-to-test element spacing at different $Z / d h$ for unconfined flow.

\section{Influence of Circumferential Angle $(\theta)$ and Jet Exit-to-Test Element (Z/dh) Distance on Pressure Coefficient}

The other critical parameters that influences the distribution of $P c$ and $P c o$ on any element are jet exit-to-test element distance $(Z / d h)$ and circumferential angle or inclination $(\theta)$ of test element. The smoke wire flow visualization helps to understand the spreading of jet on convex element [6]. From Figure 6, 7 and 8 it observed that as the $Z / d h$ value increases the $P c$ and $P c o$ drops to a lower value, that is at $Z / d h=4$ the smaller value of $P c$ and $P c o$ are obtained for both the confined and unconfined flow, that is with increase in the $Z / d h$ around $15 \%$ to $23 \%$ drop in the $P c \& P c o$ seen. As the jet exit-to-test element distance increases the drop in the jet velocity is seen due to the spreading of jet, which leads to a drop in the kinetic energy of the jet and at same time jet shifts from sub-atmospheric to atmospheric zone due to which lower value of $P c$ and $P c o$ are seen at higher $Z / d h$.

Similar drop in the $P c$ and $P c o$ are seen with change in $\theta$. As the $\theta$ change the stagnation streamline of jet gets deviated from the centerline of the test element as result $P c$ drops and this jet will be more effective when its potential core zone is between $\theta=0^{\circ}-5^{\circ}$, due to this zone around $45 \%$ to $57 \%$ higher value compared to other points. The drop in the $P c$ are seen when $\theta$ changes from $0^{\circ}$ to some other inclination. When $\theta=0^{\circ}$ maximum velocity of jet impinges on test element, as result this velocity from jet helps to get maximum dynamic pressure, as result stagnation point will reach the maximum value of $P c$ compared adjacent $\theta$ on the test element. Similar $P c$ profiles are seen in some of research works [20, 21]. The significant peaks in the distribution of $P c$ are observed between $\theta=5^{\circ}$ to $10^{\circ}$ which are $67 \%$ to $74 \%$ higher compared to other pressure coefficient values. Figure 6, 7 and 8 shows sub atmospheric regions between $\theta=22^{\circ}$ to $31^{\circ}$. For jet Reynolds number and $Z / d h$ and $D / d h$ sub atmospheric regions appeared on convex test surface. As stated by Ozmen [30], sub atmospheric zone is the evidence of a recirculation region, which is also supported by the results of Burak [20, 21] in which the negative values observed. Therefore, the local static pressure and stagnation pressure $(P c$ and $P c o)$ on the convex surface decreases with increasing distance between the nozzle exit and the convex surface for all the values of jet 
Reynolds number considered. Towards the outer regions of the surface, the nozzle-to-convex surface distance losses its effectiveness and the values of the wall jet pressure each atmospheric value.

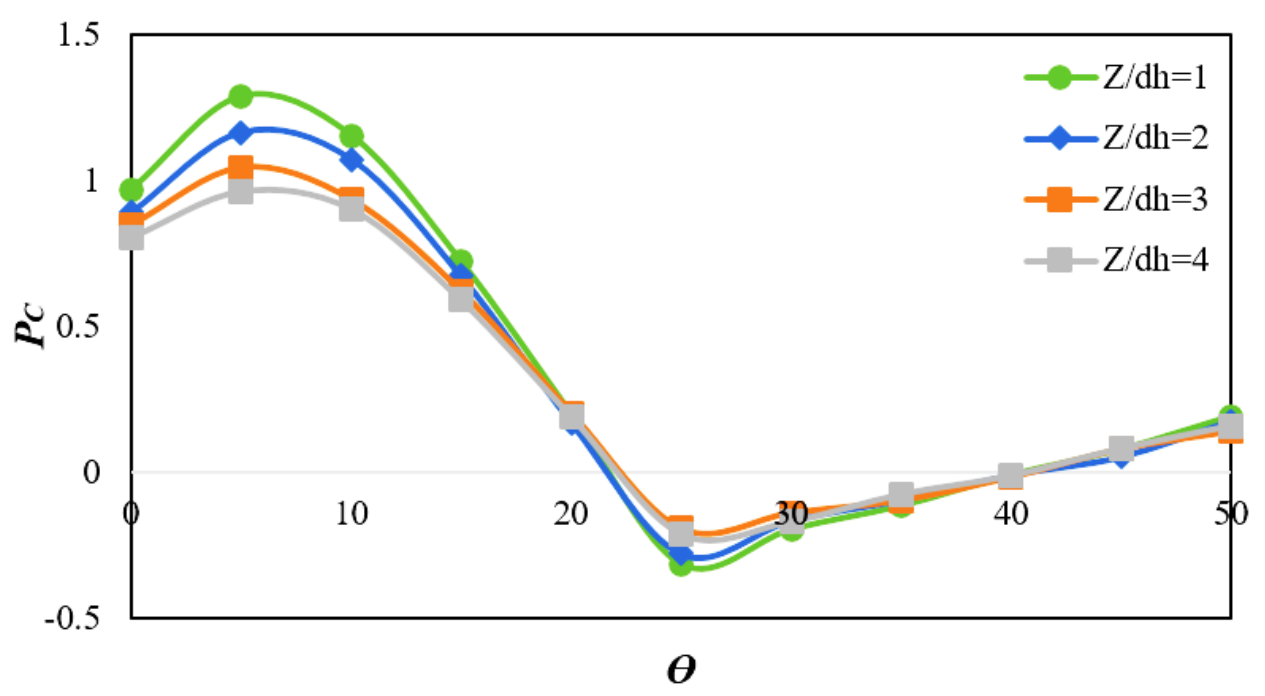

Co-axial swirl jet, $R e=65000, D / d h=4.237$

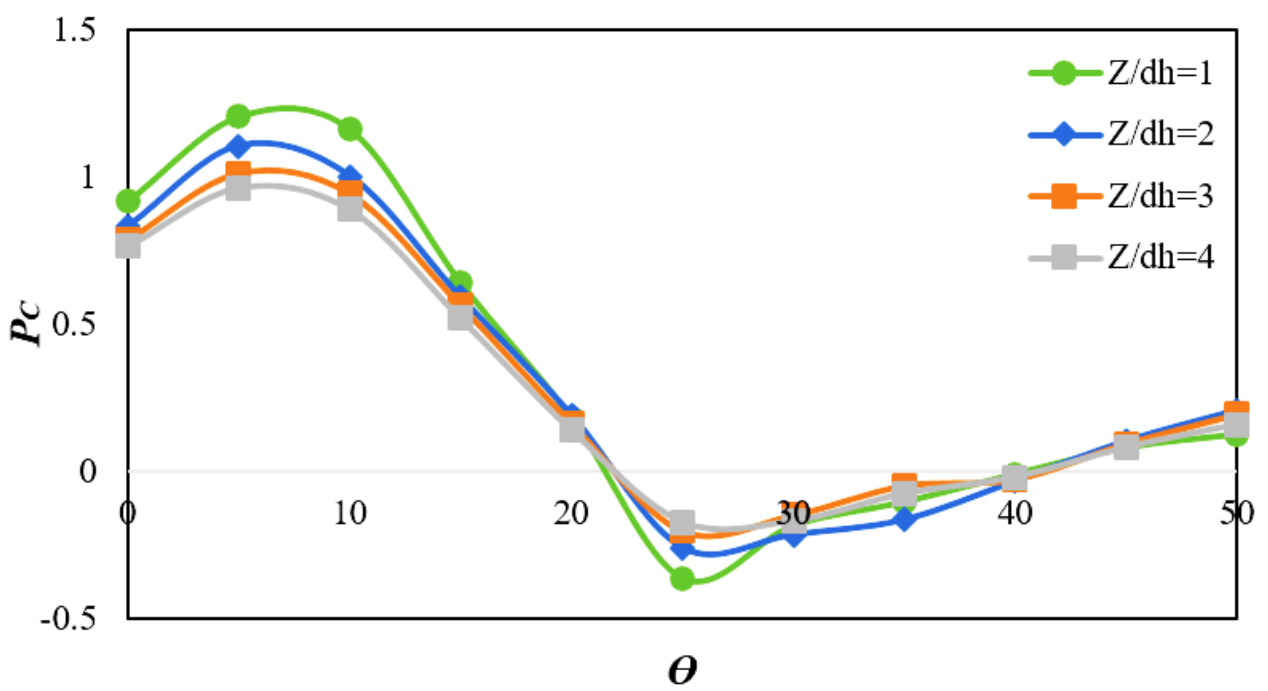

Co-axial swirl jet, $R e=50000, D / d h=4.237$

Figure 7. Variation of pressure coefficient with jet exit-to-test element spacing at different $Z / d h$ for confined flow.

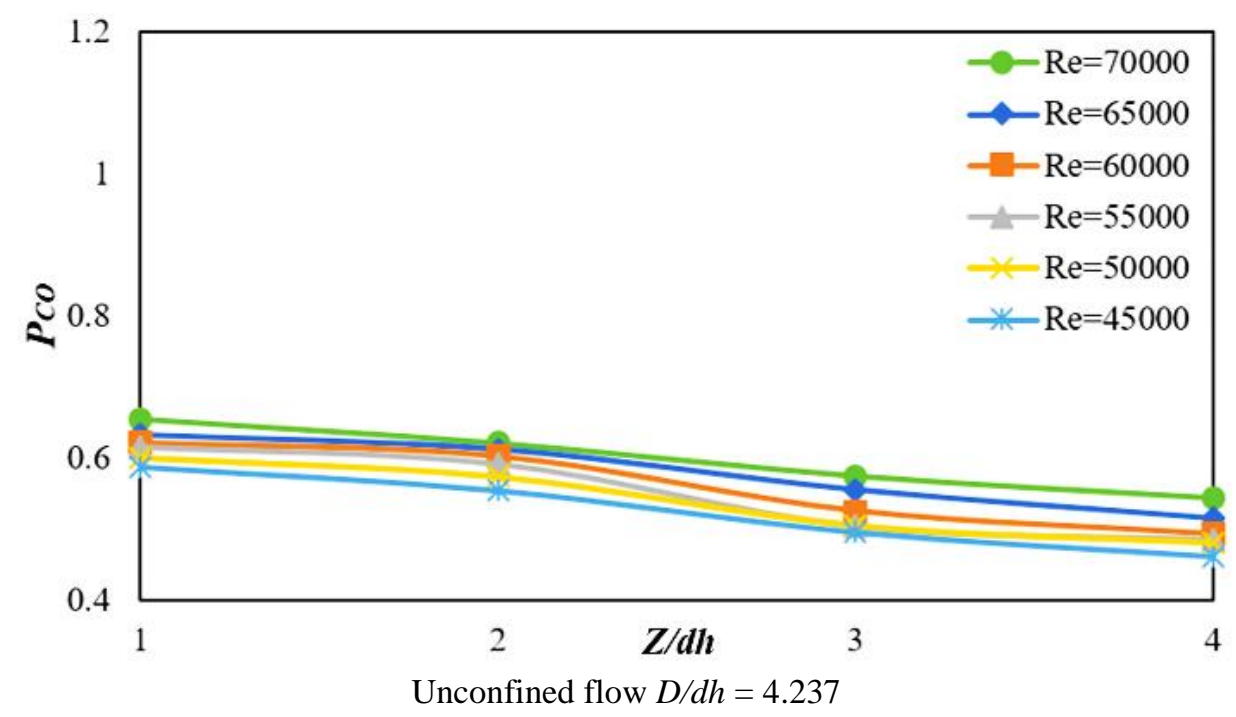




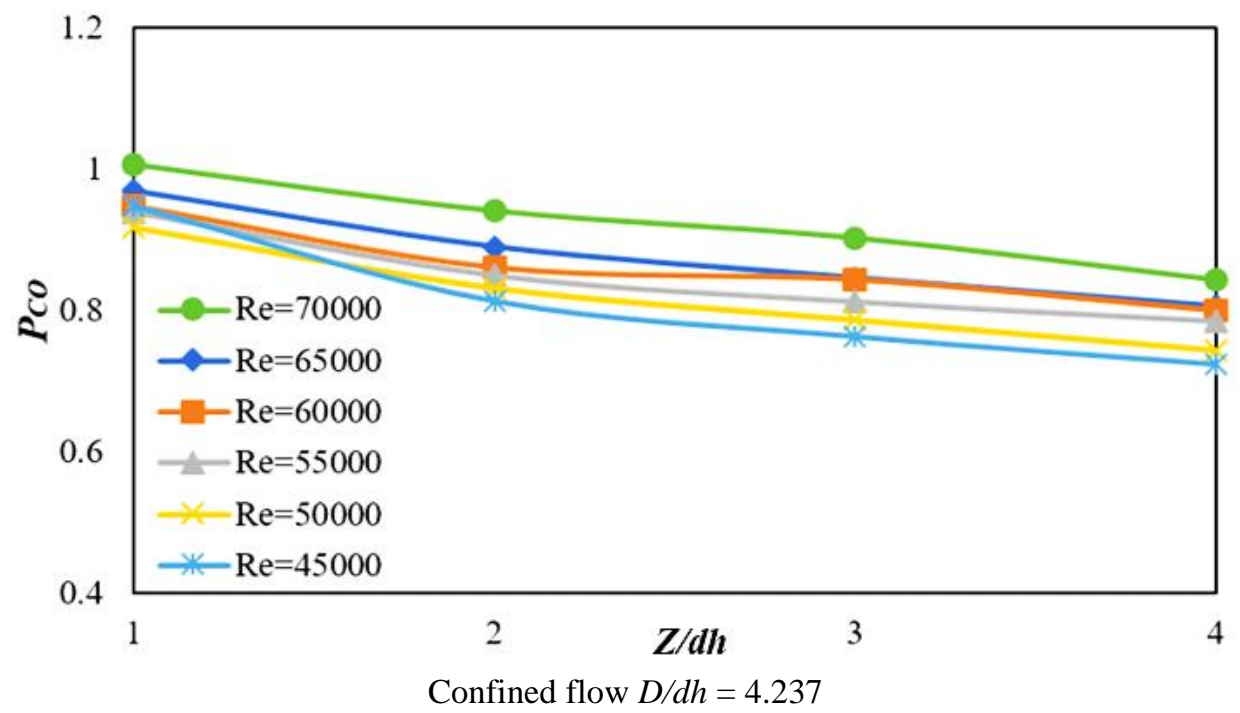

Figure 8. Variation of stagnation pressure coefficient with curvature at various jet exit-to-test element spacing.

\section{Comparison of Wall Static Pressure for Confined and Unconfined Flow}

The number studies on coaxial jets are carried using unconfined flow and only few studies are done on confined flow. In the present study, an attempt is made to know the effect of confinement on $P c$ and $P c o$ by restricting the flow of jet in defined channel using confinement tube arrangement as shown in Figure 2. A significant change is seen for $P c$ and $P c o$ profile due to this restriction in the flow, the jet will get additional energy in potential zone within the impingement channel which is shown as the evidence of a recirculation region [30]. This recirculation accelerates the kinetic energy of jet as results higher value of $P c \& P c o$ are seen for confined flow similar observations seen by Burak [20, 21]. These confinement tubes are more effective of pressure distribution when $Z / d h$ is below 2 and around $61 \%$ to $64 \%$ of enchantment in the $P c \& P c o$ is observed by the use of confinement tube. The comparison plots of $P c$ for confined and unconfined flow at $Z / d h 1 \& 4$ for $R e=50,000$ for coaxial configuration is shown in the Figure 9.

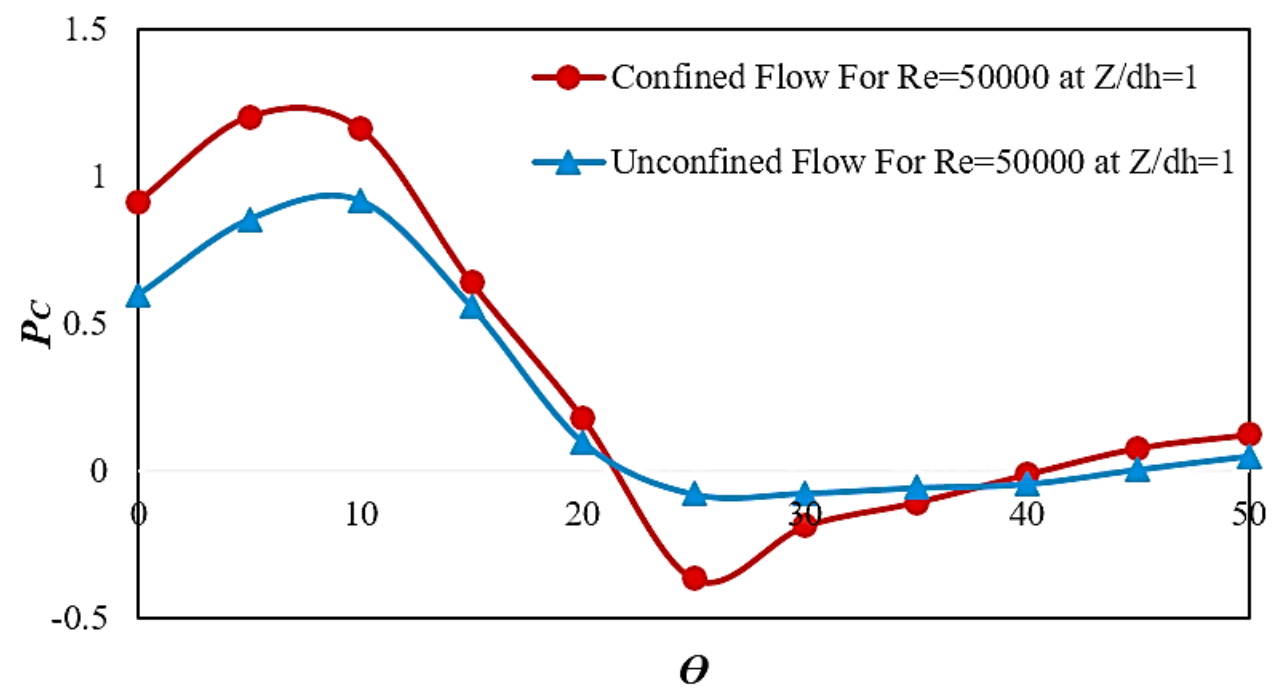




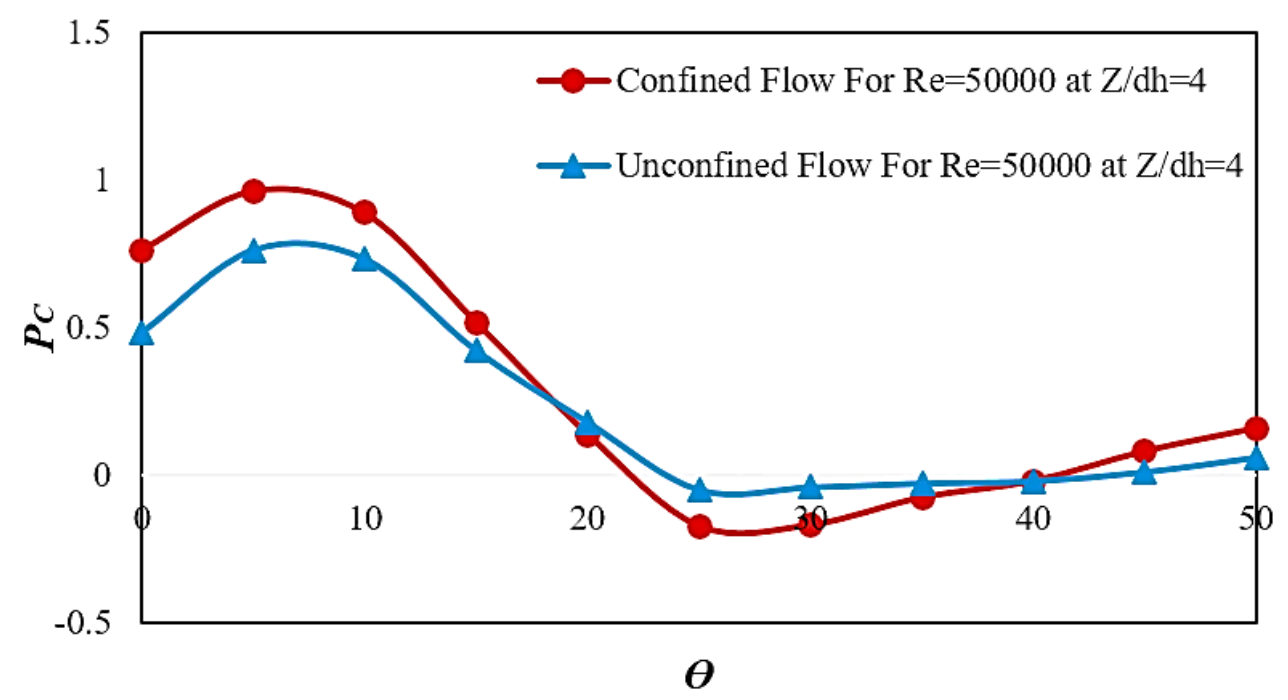

Figure 9. Comparison of pressure coefficient $P c$ for confined and unconfined flow

\section{CONCLUSIONS}

In the present study, the wall pressure distribution $(P c \& P c o)$ on convex test element by impinging air jet for confined and unconfined turbulent flow from swirling coaxial nozzle configuration is investigated experimentally. The results from the study can be summarized as below, which will help in the study of heat transfer and plays significant role in the design and analysis of gas turbine blades, Burners, combustion chambers etc.

- The pressure coefficients $P c \&$ \& $c o$ are independent of Reynolds number $(R e)$ of flow on impingement of swirling coaxial air jet on convex element for all $Z / d h$ as all curves takes same nature of curve for all $Z / d h$ and $R e$.

- For all the dimensionless $R e$ and $Z / d h$, two peak value in the pressure distribution appear on convex surface in both confined and unconfined flow. Coaxial swirl jet provides multiple mixing zones which causes increase in the share rate of jet at as result significant peaks in the pressure coefficients are seen by impinging coaxial swirl air jet on convex element between $\theta=5^{\circ}-12^{\circ}$ at all $Z / d h$ for both confined and unconfined flow.

- For all the dimensionless $R e$ and $Z / d h$ a sub atmospheric region is created on convex test surface as result at some point the pressure coefficient drops to negative values. The pressure coefficients drop in considerable range when circumferential angle $\theta$ in between $20^{\circ}-30^{\circ}$ and same nature is seen for all flow condition.

- $\quad$ For the same flow condition, the pressure coefficients $P c \&$ \& $c$ are high for Lower jet exit-to-test element distance $(Z / d h=1)$ as the jet will be in the effective potential core region, further with increase in $Z / d h$ around $15 \%-23 \%$ drop in the $P c \& P c o$ is seen and same trend is observed in both confined and unconfined flow.

- The use of confined tubes helped to get $61 \%$ to $64 \%$ higher Pc \& Pco values when compared to unconfined flow.

The use of coaxial swirl jets provide good results compared to the conventional jet for both the uniformity and intensity of pressure distribution due its better mixing and also the presence of confinement creates recirculation of jet which will be more effective in the heating and cooling of any surface by reducing thermal stress in respective region.

\section{REFERENCES}

[1] N. Celik and H. Eren, "Heat transfer due to impinging co-axial jets and the jets' fluid flow characteristics," Experimental Thermal and Fluid Science, vol. 33, no. 4, pp. 715-727, Apr. 2009, doi: 10.1016/j.expthermflusci.2009.01.007.

[2] H. Q. Yang, T. Kim, T. J. Lu, and K. Ichimiya, "Flow structure, wall pressure and heat transfer characteristics of impinging annular jet with/without steady swirling," International Journal of Heat and Mass Transfer, vol. 53, no. 19-20, pp. 4092-4100, Sep. 2010, doi: 10.1016/j.ijheatmasstransfer.2010.05.029.

[3] W. Lee, Y. Park, K. Kwon, and R. Taghavi, "Control of shear perturbation in coaxial swirling turbulent jets," Aerospace Science and Technology, vol. 14, no. 7, pp. 472-486, Oct. 2010, doi: 10.1016/j.ast.2010.03.002.

[4] K. K. J. Ranga Dinesh, M. P. Kirkpatrick, and K. W. Jenkins, "Investigation of the influence of swirl on a confined coannular swirl jet," Computers \& Fluids, vol. 39, no. 5, pp. 756-767, May 2010, doi: 10.1016/J.COMPFLUID.2009.12.004.

[5] N. Celik, "Effects of the surface roughness on heat transfer of perpendicularly impinging co-axial jet," Heat and Mass Transfer/Waerme- und Stoffuebertragung, vol. 47, no. 10, pp. 1209-1217, Oct. 2011, doi: 10.1007/s00231-011-0785-9.

[6] A. Adzlan and H. Gotoda, "Experimental investigation of vortex breakdown in a coaxial swirling jet with a density difference," Chemical Engineering Science, vol. 80, pp. 174-181, Oct. 2012, doi: 10.1016/J.CES.2012.05.027. 
[7] A. Ianiro and G. Cardone, "Heat transfer rate and uniformity in multichannel swirling impinging jets," Applied Thermal Engineering, vol. 49, pp. 89-98, Dec. 2012, doi: 10.1016/J.APPLTHERMALENG.2011.10.018.

[8] C. Nuntadusit, M. Wae-hayee, A. Bunyajitradulya, and S. Eiamsa-ard, "Heat transfer enhancement by multiple swirling impinging jets with twisted-tape swirl generators," International Communications in Heat and Mass Transfer, vol. 39, no. 1, pp. 102-107, Jan. 2012, doi: 10.1016/J.ICHEATMASSTRANSFER.2011.10.003.

[9] H. Lu, H. Liu, W. Li, and J. Xu, "Factors influencing the characterization of bubbles produced by coaxial gas-particle jet flow," Fuel, vol. 108, pp. 723-730, Jun. 2013, doi: 10.1016/J.FUEL.2013.01.078.

[10] T. H. New and E. Tsioli, "Effects of area-ratio on the near-field flow characteristics and deflection of circular inclined coaxial jets," Experimental Thermal and Fluid Science, vol. 54, pp. 225-236, Apr. 2014, doi: 10.1016/J.EXPTHERMFLUSCI.2013.12.022.

[11] M. Fénot, E. Dorignac, and G. Lalizel, "Heat transfer and flow structure of a multichannel impinging jet," International Journal of Thermal Sciences, vol. 90, pp. 323-338, Apr. 2015, doi: 10.1016/J.IJTHERMALSCI.2014.12.006.

[12] M. Wannassi and F. Monnoyer, "Fluid flow and convective heat transfer of combined swirling and straight impinging jet arrays," Applied Thermal Engineering, vol. 78, pp. 62-73, Mar. 2015, doi: 10.1016/J.APPLTHERMALENG.2014.12.043.

[13] S. Eiamsa-ard, K. Nanan, and K. Wongcharee, "Heat transfer visualization of co/counter-dual swirling impinging jets by thermochromic liquid crystal method," International Journal of Heat and Mass Transfer, vol. 86, pp. 600-621, Jul. 2015, doi: 10.1016/J.IJHEATMASSTRANSFER.2015.03.031.

[14] H. Boualia, A. Hidouri, M. Chrigui, and J.-C. Sautet, "Experimental investigation of central jet displacements on the turbulence and gas dynamics of a coaxial burner," Applied Thermal Engineering, vol. 116, pp. 303-315, Apr. 2017, doi: 10.1016/J.APPLTHERMALENG.2017.01.085.

[15] P. Balakrishnan and K. Srinivasan, "Jet noise reduction using co-axial swirl flow with curved vanes," Applied Acoustics, vol. 126, pp. 149-161, Nov. 2017, doi: 10.1016/J.APACOUST.2017.05.009.

[16] S. Chouaieb, W. Kriaa, H. Mhiri, and P. Bournot, "Swirl generator effect on a confined coaxial jet characteristics," International Journal of Hydrogen Energy, vol. 42, no. 48, pp. 29014-29025, Nov. 2017, doi: 10.1016/J.IJHYDENE.2017.08.061.

[17] Z. U. Ahmed, Y. M. Al-Abdeli, and F. G. Guzzomi, "Heat transfer characteristics of swirling and non-swirling impinging turbulent jets," International Journal of Heat and Mass Transfer, vol. 102, pp. 991-1003, Nov. 2016, doi: 10.1016/J.IJHEATMASSTRANSFER.2016.06.037.

[18] Z. U. Ahmed, Y. M. Al-Abdeli, and F. G. Guzzomi, "Flow field and thermal behaviour in swirling and non-swirling turbulent impinging jets," International Journal of Thermal Sciences, vol. 114, pp. 241-256, Apr. 2017, doi: 10.1016/J.IJTHERMALSCI.2016.12.013.

[19] E. Zeiny, M. Farhadi, and K. Sedighi, "Numerical investigation of the simultaneous influence of swirling flow and obstacles on plate in impinging jet," International Journal of Heat and Technology, vol. 35, no. 1, pp. 59-66, Mar. 2017, doi: 10.18280/ijht.350108.

[20] B. Markal, "Experimental investigation of heat transfer characteristics and wall pressure distribution of swirling coaxial confined impinging air jets," International Journal of Heat and Mass Transfer, vol. 124, pp. 517-532, Sep. 2018, doi: 10.1016/J.IJHEATMASSTRANSFER.2018.03.101.

[21] B. Markal and O. Aydin, "Experimental investigation of coaxial impinging air jets," Applied Thermal Engineering, vol. 141, pp. 1120-1130, Aug. 2018, doi: 10.1016/J.APPLTHERMALENG.2018.06.066.

[22] A. M. Hanchinal et al., "Study on Impingement of Air Jet from Orifice on Convex Surface for Unconfined Flow," 2018. [Online]. Available: www.ijraset.com.

[23] A. M. Hanchinal, A. Biradar, A. Karabhari, D. Pujar, V. Minajigi, and A. Professor, "Distribution of Wall Static Pressure on Flat Plate by Impenjing Air Jet from Orifice for Turbulent Flow," 2018. [Online]. Available: www.ijraset.com.

[24] S. Mohamed Illyas, B. R. Ramesh Bapu, and V. Venkata Subba Rao, "Heat transfer and flow visualization of swirling impinging jet on flat surface using helicoid inserts," Journal of Visualization, vol. 21, no. 5, pp. 729-749, Oct. 2018, doi: 10.1007/s12650-018-0493-3.

[25] N. V. S. Shankar and R. Shankar, "Experimental Investigation into Heat Transfer during Swirl Jet Impingement,” 2018. [Online]. Available: http://www.ripublication.com.

[26] K. Kunnarak, P. Somravysin, S. Eiamsa-Ard, and V. Chuwattanakul, "Impingement cooling by round jet with longitudinal swirling strip," International Journal of Mechanical Engineering and Robotics Research, vol. 7, no. 2, pp. 179-183, Mar. 2018, doi: 10.18178/ijmerr.7.2.179-183.

[27] S. A. Schumaker and J. F. Driscoll, "Coaxial turbulent jet flames: Scaling relations for measured stoichiometric mixing lengths," Proceedings of the Combustion Institute, vol. 32, no. 2, pp. 1655-1662, Jan. 2009, doi: 10.1016/J.PROCI.2008.06.051.

[28] A. M. Hanchinal and V. v. Katti, "Effect of orifice geometry and orifice-to-test section spacing on distribution of wall static pressure on a convex surface," Journal of Mechanical Engineering and Sciences, vol. 13, no. 2, pp. 4835-4845, 2019, doi: 10.15282/jmes.13.2.2019.05.0402.

[29] G. M. Carlomagno and A. Ianiro, "Thermo-fluid-dynamics of submerged jets impinging at short nozzle-to-plate distance: A review," Experimental Thermal and Fluid Science, vol. 58, pp. 15-35, Oct. 2014, doi: 10.1016/J.EXPTHERMFLUSCI.2014.06.010. 
[30] Y. Ozmen, "Confined impinging twin air jets at high Reynolds numbers," Experimental Thermal and Fluid Science, vol. 35, no. 2, pp. 355-363, Feb. 2011, doi: 10.1016/J.EXPTHERMFLUSCI.2010.10.006. 